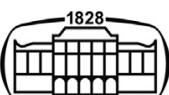

AKADÉMIAI KIADÓ

\section{Acta Veterinaria \\ Hungarica}

69 (2021) 2, 116-124

DOI:

$10.1556 / 004.2021 .00024$

(c) 2021 The Author(s)

\title{
Digital phonocardiography of cardiac arrhythmias in dogs - Preliminary experiences
}

\author{
MÁRTON BALOGH ${ }^{1 *} \odot$, FRUZSINA KOCH ${ }^{2}$, LÁSZLÓ SIVER ${ }^{3}$, \\ ATTILA KRIMA $^{4}$ and KÁROLY VÖRÖS ${ }^{1}$
}

\author{
${ }^{1}$ Department and Clinic of Internal Medicine, University of Veterinary Medicine Budapest, István \\ u. 2, H-1078 Budapest, Hungary \\ ${ }^{2}$ Mátyás Veterinary Centre, Dunaharaszti, Hungary \\ ${ }^{3}$ SchiAb Veterinary Centre, Érd, Hungary \\ ${ }^{4}$ Innomed Medical Co. Ltd., Budapest, Hungary
}

Received: 2 March 2021 • Accepted: 9 June 2021

Published online: 6 July 2021

\section{RESEARCH ARTICLE}

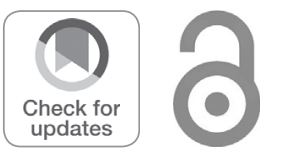

\begin{abstract}
Electronic stethoscopes and digital phonocardiograms (DPCGs) can be applied when diagnosing cardiac murmurs, but their use for cardiac arrhythmias is not described in veterinary medicine. Data of 10 dogs are presented in this preliminary study, demonstrating the applicability of these techniques. Although the number of artefacts and the amount of baseline noise produced by the two digitising systems used did not differ, the Welch Allyn Meditron system or similar ones capable of simultaneous recording of electrocardiograms (ECGs) and DPCGs provide a better option for clinical research and education, whilst the $3 \mathrm{M}$ Littmann 3200 system might be more suitable for everyday clinical settings. A combined system with simultaneous phonocardiogram and ECG, especially with wireless transmission, might be a solution in the future.
\end{abstract}

\section{KEYWORDS}

digital phonocardiography, heart, arrhythmia, electrocardiography, dog

\section{INTRODUCTION}

Cardiac auscultation plays a critical role in the clinical examination in human and veterinary medicine. It commonly helps identify cardiac murmurs and arrhythmias. The auscultatory findings can prompt further diagnostic techniques, e.g. thoracic radiography, echocardiography, and electrocardiography. Auscultation is safe, cheap, easy and quick, thus providing an excellent screening test for most dogs and cats. Furthermore, clinicians can gain valuable information about the underlying disease process and its severity based on auscultatory findings (Ljungvall et al., 2014; Caivano et al., 2018; Rishniw, 2018).

Various investigators have compared conventional stethoscopes (CS) and electronic stethoscopes (ES) for their ability to identify murmurs in people (Philip and Raemer, 1986; Grenier et al., 1998; Hoyte et al., 2005; Tavel, 2006) and dogs (Vörös et al., 2012; Szilvási et al., 2013). Furthermore, our group has also used both types of stethoscopes in a study on the occurrence of mitral valve insufficiency in healthy Beagle dogs (Vörös et al., 2015). However, only one study has focused on the sensitivity of electronic stethoscopes in identifying cardiac arrhythmias in people (Zenk et al., 2004). Blass et al. (2013) compared a digital, electronic stethoscope to a conventional, acoustic stethoscope for detecting cardiac murmurs and gallop

${ }^{*}$ Corresponding author. Tel.: +361 4784132.

E-mail: balogh.marton@univet.hu sounds in cats. However, to the best of our knowledge, there are no studies on examining the diagnosis or characteristics of arrhythmias recorded by digital electronic stethoscopes.

In addition to the increased sensitivity of digital electronic stethoscopes, some have the capability to digitise analogue sound waves via an analogue/digital converter (Tavel, 2006; Germanakis et al., 2008; Vörös et al., 2011). These digitalised sounds can be transferred to a 
computer equipped with a proper software for recording, storing and further processing. The digitalised sounds can be displayed as digital phonocardiograms, which represent soundwaves as a time-amplitude graph, with or without a synchronous electrocardiogram (ECG) (Tavel, 2006; Germanakis et al., 2008). We have comprehensively described this methodology in our earlier publication on recording canine murmurs (Vörös et al., 2011).

Digital phonocardiograms allow clinicians to visualise and analyse heart murmurs (Tavel, 2006; Noponen et al., 2007; Germanakis et al., 2008; Vörös et al., 2011, 2012; Szilvási et al., 2013; Szilvási and Vörös, 2014), and they have been used in human patients with murmurs for nearly three decades (Tavel, 1996; Dahl et al., 2002; Germanakis et al., 2008). Our research group was the first to report the use of digital phonocardiograms in clinical settings for assessing canine murmurs (Vörös et al., 2011, 2012; Szilvási et al., 2013). Marinus et al. (2017) examined the ability of digital phonocardiography to differentiate innocent cardiac murmurs from those caused by congenital cardiac anomalies in puppies. Reisse (2008) and Fraune (2010) published digital phonocardiographic recordings of murmurs in cattle and horses, respectively. Ljungvall et al. (2009) examined the spectral characteristics of murmurs associated with mitral valve disease, whilst Kvart and Häggström (2002) published an audio textbook of heart sounds and murmurs that included numerous phonocardiograms which were possibly recorded in an analogue way, although the authors did not indicate their recording technique.

Based on the experiences and on the digitalised sound collections of our study group, a heart sound library of the most common canine cardiac murmurs was established in co-operation between the E-learning Consulting Department (Zelda) and the Small Animal Clinic of the University of Veterinary Medicine Hannover Foundation (TiHo), and the Department and Clinic of Internal Medicine of the University of Veterinary Medicine Budapest. This sound collection is freely available under the web site https://www. tiho-hannover.de/studium-lehre/zelda/e-learning-beratung/ lernmedien-und-lernprogramme/heartsound-library (Vörös et al., 2010).

Digital phonocardiograms form an important part of cardiac pedagogy, and reports exist on using them in telecardiology in human medicine (Dahl et al., 2002; Germanakis et al., 2008; Mahnke et al., 2008; Germanakis and Kalmanti, 2009). Ehlers et al. (2010) reported favourable experiences when teaching veterinary students by listening to cardiac murmurs off-line, whilst providing digital phonocardiograms available with the free audio library described above with the teaching material.

Only one human study has examined the use of digital phonocardiography in the evaluation of cardiac arrhythmias (Zenk et al., 2004). A synchronous ECG should be recorded with the phonocardiogram; this is only possible with dedicated instruments, such as the Welch Allyn Meditron Electronic Stethoscope. In addition, visualisation of arrhythmias on the phonocardiogram is more susceptible to technical disturbances (artefacts) compared to recorded cardiac murmurs, based on our preliminary observations. Only one article describes the use of sound recordings of equine murmurs and arrhythmias recorded and played back in an analogue (traditional) way for education (Naylor et al., 2001). Digital phonocardiograms of arrhythmias might be more suitable for teaching students compared to traditional analogue sound recordings that lack synchronous ECGs.

Therefore, we sought to record canine arrhythmias using digital phonocardiography with simultaneously acquired ECGs and to compare their diagnostic value with the ECGs appearing on the phonocardiogram itself and with those recorded on a diagnostic multi-lead electrocardiograph.

We then compared the recording quality of two electronic stethoscopes for their ability to produce digital phonocardiograms that could be used for didactic or diagnostic purposes.

\section{MATERIALS AND METHODS}

\section{Dogs and study design}

We examined 32 dogs in order to adapt the digital phonocardiogram recording technique to cardiac arrhythmias. Of these, 25 dogs only had a physiological respiratory arrhythmia. These animals arrived at the Department and Clinic of Internal Medicine, University of Veterinary Medicine Budapest for various endoscopic (otoscopy, gastroscopy, respiratory examinations) procedures and to the SchiAb Veterinary Centre, Érd, Hungary for planned surgical interventions. Of these 25 dogs, 16 were anaesthetised before the planned endoscopy or surgery. In these cases, all animals underwent procedures requiring general anaesthesia, which were unrelated to our examination. Dogs were premedicated and induced with $0.5 \mathrm{mg} / \mathrm{kg}$ diazepam and $5 \mu \mathrm{g} / \mathrm{kg}$ dexmedetomidine iv. or with $0.5 \mathrm{mg} / \mathrm{kg}$ diazepam and $6 \mathrm{mg} / \mathrm{kg}$ ketamine. The inhalation anaesthesia was maintained with isoflurane. An analysis of cardiac alterations elicited by anaesthesia (e.g., bradycardia or atrioventricular blocks) did not belong to the goals of the present study. The remaining 9 dogs were examined awake.

Seven of the 32 dogs were presented for evaluation of cardiac disease. All seven dogs had tachyarrhythmias: atrial fibrillation $(n=2)$, atrial premature complexes $(n=2)$, ventricular premature complexes $(n=2)$ and paroxysmal ventricular tachycardia $(n=1)$. These dogs were examined without sedation.

In all cases, written consent was gained from each owner before starting the study. The implemented procedures were compliant with the guidance of the Animal Welfare Committee of the University of Veterinary Medicine, Budapest.

\section{Physical examinations}

All dogs underwent a detailed physical examination with special regard to the cardiorespiratory system. One investigator (KV) performed both conventional cardiac auscultation (with a Sprague Rappaport type conventional, acoustic stethoscope) and digital auscultation (with a $3 \mathrm{M}$ Littmann 


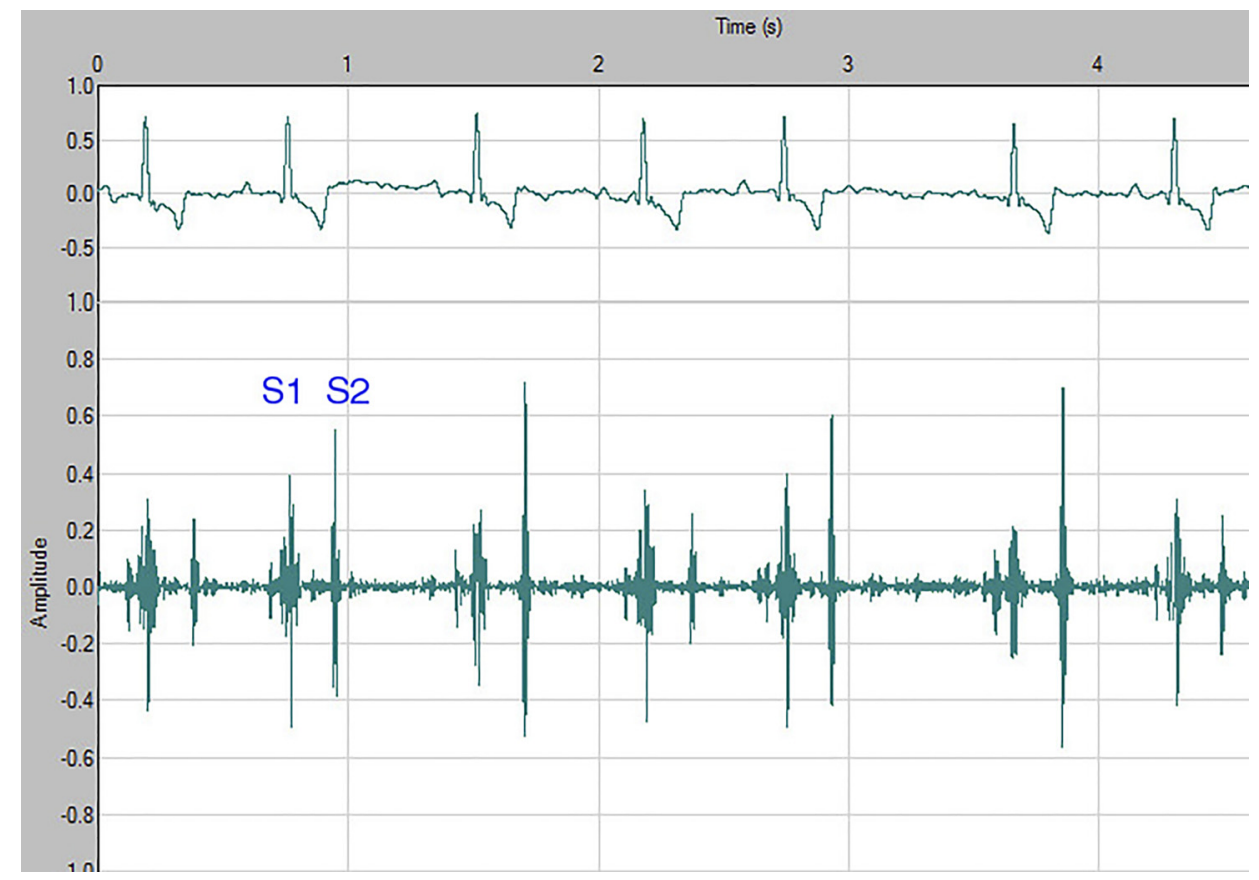

Fig. 1. Digital phonocardiogram (DPCG) of a healthy Beagle recorded with the Welch Allyn Meditron system. The X axis represents time, the $\mathrm{Y}$ axis represents the amplitudes/wave forms of the heart sounds. The upper part of the image shows the simultaneously recorded (synchronous) Einthoven lead 2 bipolar electrocardiogram (ECG). S1: Heart sound 1, S2: Heart sound 2. (From Vörös et al.: Acta Vet. Hung. 2011; 59, 23-35, with permission)

Electronic Stethoscope Model 3200 and a Meditron Welch Allyn electronic stethoscope).

\section{Echocardiography}

Echocardiography was performed as described for routine clinical echocardiography (Bonagura and Fuentes, 2015; Brown et al., 2015; Vörös et al., 2015).

\section{Digital phonocardiography}

Digital phonocardiograms were made and processed with the Welch Allyn Meditron Master Elite Stethoscope and Analyser System (Welch Allyn Corp., USA) as described earlier in humans and in dogs with cardiac murmurs (Germanakis et al., 2008; Vörös et al., 2011). This sound digitalising system includes the recording of synchronous, Einthoven lead II ECGs (Fig. 1).

The digital files were stored and analysed on a personal computer as .wav (16-bit waveform) files. These Meditron .wav files contain both the simultaneous ECG (left channel) and sound (right channel) data and were replayed and analysed with the dedicated software of the Welch Allyn Meditron digitising software. The .wav files were converted to conventional .wav and .mp3 files by using the freely available shareware program Audacity ${ }^{\circledR}$ (https://www. audacityteam.org). The original Meditron digital phonocardiogram video recordings were also converted from the original Meditron .wav files into video .mpg files with the CamStudio $^{\mathrm{TM}}$ (www.camstudio.org), similarly to the digital phonocardiogram recordings of the cardiac murmurs that can be found in our heart sound library (Vörös et al., 2010).
Awake dogs were examined standing, with two adhesive flat ECG electrodes fixed with Ramofix flexible band on the thorax and one on the left gluteal region (Fig. 2) as reported earlier by Szilvási and Vörös (2014). The three electrodes allow the recording of modified versions of the conventional Einthoven bipolar leads, with Lead II corresponding to the signal produced by the white and red electrodes. This was

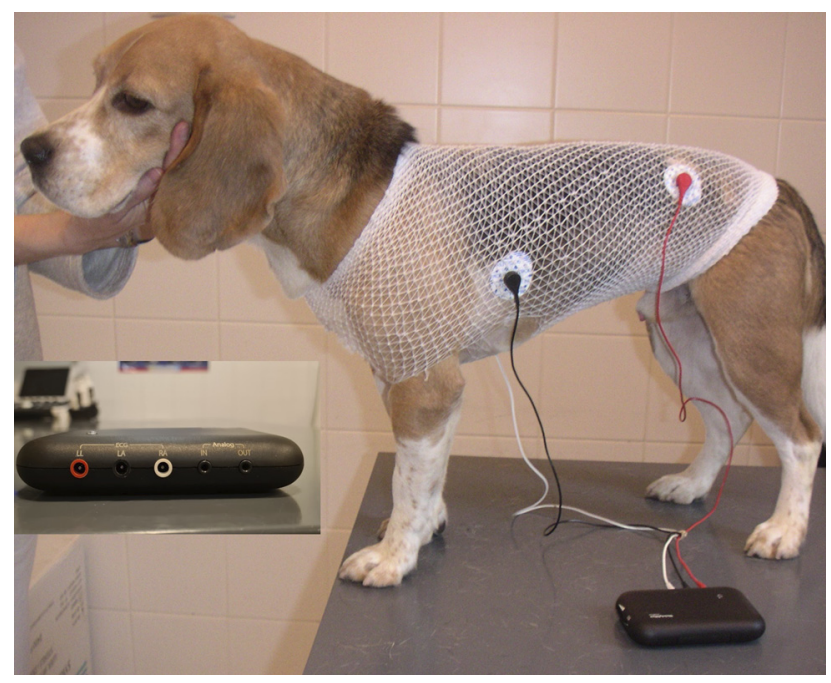

Fig. 2. Fixation of the ECG adhesive electrodes to the chest and to the hip region using Ramofix flexible band. The A/D converter, which transmits the digitalised sounds to the computer, can be seen beside the dog, along with its electrode cables. (From Szilvási and Vörös: Magy. Allatorvosok 2014; 136, 291-299, with permission) 
made to provide good-quality recordings in standing animals as shown on Fig. 2. Sedated dogs were examined in right lateral recumbency with the Welch Allyn Meditron system, where clip electrodes on the limbs were used for recording the ECG signals as the traditional method (Edwards, 1987; Tilley and Burtnick, 2009). In this group, recordings were also obtained with the $3 \mathrm{M}$ Littmann Electronic Stethoscope Model 3200 to produce digital phonocardiograms with the relevant software, as described by Marinus et al. (2017).

\section{Electrocardiography}

An Innobase Pico type 7-channel Holter ECG (Innomed Medical Inc., Hungary) was used, equipped with clamp electrodes to follow cardiac function and rhythm during the study. Standard bipolar Einthoven I, II, III as well as unipolar Goldberger aVR, aVL, aVF leads, and one Wilson thoracic (precordial) lead were recorded simultaneously with this instrument. Together with the Holter recordings, the Welch Allyn Meditron system was also used to produce synchronous ECG curves parallel with the digitalised phonocardiograms. To compare the events on the Holter ECGs with the digital phonocardiogram recordings, we created a unique artefact on the Holter ECG recording at the start of the digital phonocardiogram recording by touching and moving one of the electrodes by hand for $1 \mathrm{~s}$.

\section{Comparison and analysis of the ECGs and Welch Allyn digital phonocardiograms}

The ECG recordings were examined based on two parameters: (1) deviation from the baseline, and (2) the number of artefacts.

On the ECG recordings of the Holter instrument and on the digital phonocardiograms, the maximal baseline deflection was calculated, by measuring the difference between maximal and minimal points of the baseline on the $\mathrm{Y}$ axis, presented in $\mathrm{mV}$. For the Welch Allyn Meditron electronic stethoscope, only a single, transthoracic bipolar ECG was recorded and evaluated (Fig. 3). For Holter-produced ECGs, all seven leads were examined (Fig. 4).

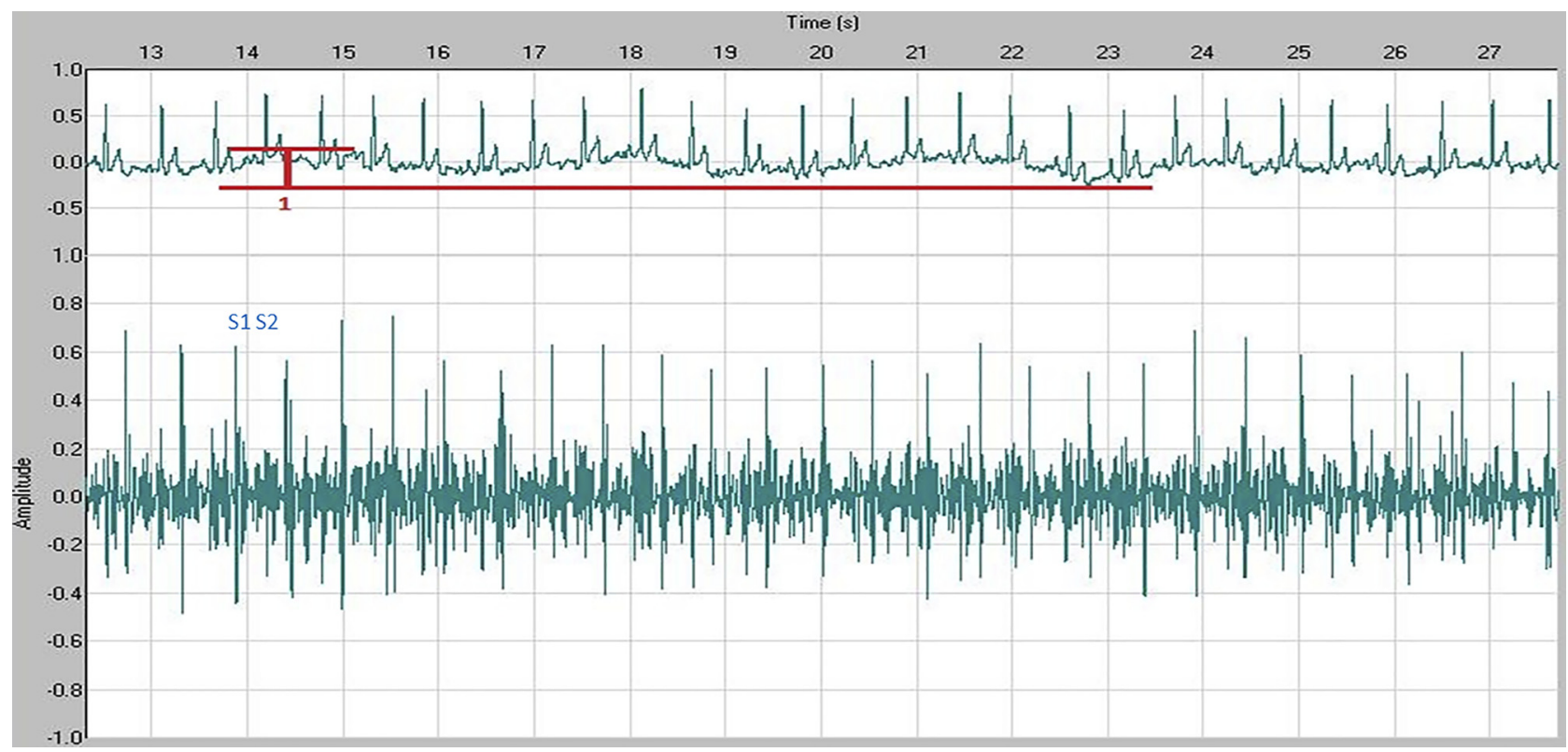

Fig. 3. Measurement of the ECG baseline deviation on a digital phonocardiogram (DPCG) recorded with the Welch Allyn Meditron system. The baseline deviation is the difference between the highest (upper, smaller horizontal line) and the lowest (lower horizontal line) points of the baseline, in $\mathrm{mV}$. S1: first heart sound, S2: second heart sound

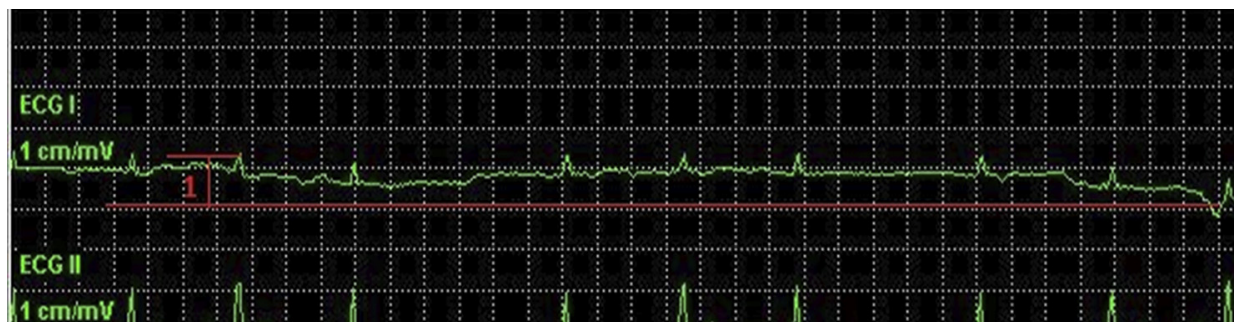

Fig. 4. Measurement of the ECG baseline deviation of Einthoven bipolar lead 1 on an ECG recording made with the Innomed Holter ECG system. The baseline deviation is the difference between the highest (upper, smaller horizontal line) and the lowest (lower, horizontal line) points of the baseline, in (1) $\mathrm{mV}$ 
Artefacts were counted over a 12 -sec period, in a manner consistent with the examination of baseline deviation, on the single lead in the case of Meditron recordings, and on all seven leads in the case of Holter recordings. Because artefacts tend to be absent in some leads on the 7-lead ECG, we examined all seven leads separately.

We then examined the ECGs of the seven dogs with pathological arrhythmias by comparing the presence of the extrasystole on ECG and digital phonocardiogram recorded simultaneously by the Welch Allyn Meditron system with the extrasystole present on the 7-lead Holter ECG.

\section{Comparison of digital stethoscopes}

We then compared digital phonocardiograms recorded by Welch Allyn Meditron and Littmann digital stethoscopes in 10 cases. First, we measured baseline noise and heart sound amplitude, using an image editing software (Adobe Photoshop CC 2018). We constructed a ratio of average S1 amplitude in pixels to average baseline noise amplitude. With this ratio, a high value means a more distinguishable heart sound. We then counted the number of artefacts over a 12-sec period.

\section{Statistical analyses}

We compared the counts of artefacts between the two electronic stethoscopes by Mann-Whitney U tests, corrected for small sample sizes, because only one dog had data obtained by both stethoscopes. We compared the artefacts between the Welch Allyn Meditron and the Holter ECGs using Signed Ranks tests, corrected for small sample sizes. All statistical analyses were performed using a free online statistical calculator (http://vassarstats.net/).

\section{RESULTS}

\section{Technique and applicability of ECG and digital phonocardiogram recording methods of arrhythmias}

We could only obtain standardised, reproducible data from 10 out of the 16 sedated dogs.

In general, we obtained good-quality ECGs in the 9 standing, awake dogs and in the 10 sedated dogs using the ECG system of the Meditron Welch Allyn electronic stethoscope.

Both electronic stethoscopes produced phonocardiograms that allowed identification of the cardiac rhythm in all 10 cases included in the study (Table 1). Even in cases with higher baseline noise, we could identify a physiologic heartbeat from the digital phonocardiogram or the corresponding ECG. We found that the Meditron Welch Allyn electronic stethoscope produced recordings of reasonable quality (where both baseline noise and artefact count could be evaluated) in five cases, but not in the other five. Single examples of goodand bad-quality recordings are presented in Figs 5 and 6, respectively. On the other hand, we found it harder to create digital phonocardiograms of adequate quality with the Littmann 3200 electronic stethoscope which produced 3 adequate and 7 inadequate quality recordings (Fig. 7).
Table 1. Baseline deviation of the ECG signals on the Innomed Holter and on the Welch Allyn Meditron DPCG recordings

\begin{tabular}{|c|c|c|c|c|c|}
\hline Case & Breed & $\begin{array}{l}\text { Age } \\
\text { (year) }\end{array}$ & $\begin{array}{c}\text { ECG } \\
\text { diagnosis }\end{array}$ & $\begin{array}{c}\text { Innomed } \\
\text { Holter } \\
(\mathrm{mV})\end{array}$ & $\begin{array}{c}\text { Welch } \\
\text { Allyn } \\
\text { Meditron } \\
(\mathrm{mV})\end{array}$ \\
\hline 1 & $\begin{array}{c}\text { Doberman } \\
\text { Pinscher }\end{array}$ & 5 & PSA & 3.9 & $\mathrm{X}$ \\
\hline 2 & $\begin{array}{c}\text { American } \\
\text { Bulldog }\end{array}$ & 0.3 & SR & 1.14 & 0.3 \\
\hline 3 & $\begin{array}{l}\text { Mixed } \\
\text { breed }\end{array}$ & 1 & PSA & 2.9 & 0.01 \\
\hline 4 & Rottweiler & 4 & PVT & 5.8 & 0.1 \\
\hline 5 & $\begin{array}{l}\text { Cane } \\
\text { Corso }\end{array}$ & 3 & SR & $\mathrm{X}$ & $\mathrm{X}$ \\
\hline 6 & $\begin{array}{c}\text { German } \\
\text { Shepherd } \\
\text { Dog }\end{array}$ & 2 & SR & 10.5 & 0 \\
\hline 7 & Chihuahua & 3 & SR & 7.4 & $\mathrm{X}$ \\
\hline 8 & $\begin{array}{l}\text { English } \\
\text { Bulldog }\end{array}$ & 0.9 & SR & 19.7 & 0.1 \\
\hline 9 & $\begin{array}{c}\text { Bichon } \\
\text { Havanese }\end{array}$ & 9 & SR & 1 & 0.2 \\
\hline 10 & $\begin{array}{c}\text { Mixed } \\
\text { breed }\end{array}$ & 0.9 & PSA & $\mathrm{X}$ & 0.5 \\
\hline
\end{tabular}

$\mathrm{mV}$ : millivolts; PSA: physiologic sinus arrhythmia; SR: sinus rhythm; PVT: paroxysmal ventricular tachycardia; X: baseline deviation could not be evaluated due to high noise.

\section{Comparison of the Welch Allyn Meditron and the Holter systems for ECG recording of arrhythmias}

The ECGs obtained with the Welch Allyn Meditron electronic stethoscope and the Holter ECG demonstrated substantial baseline artefact which affected interpretation of the ECG in $20-30 \%$ of the cases. Overall - when not on a level that prevented interpretation - the Welch Allyn Meditron ECG appeared to have a smaller baseline artefact than the Holter ECG, although we did not make a statistical comparison of the amplitude of the artefact.

In five cases, the high baseline noise hindered artefact counting (marked with an $\mathrm{X}$ in Table 2). The number of artefacts on ECGs produced by the Welch Allyn Meditron and the Holter ECG where we could obtain counts did not differ $(\mathrm{W}=17$, critical $\mathrm{W}=21)$.

\section{Comparison of the Welch Allyn Meditron and the 3M Littmann 3200 systems for digital phonocardiographic recording of arrhythmias}

There was no significant difference between the noise produced by the two systems (Table 3 ). Over $50 \%$ of the cases examined with either stethoscope had such high noise (marked with $\mathrm{X}$ ) that we were unable to count the number of artefacts. The number of artefacts produced by the Welch Allyn Meditron and the 3M Littmann 3200 electronic stethoscopes did not differ $\left(\mathrm{U}_{\mathrm{A}}: 10.5\right.$, Critical $\mathrm{U}_{\mathrm{A}}: 1$ to 14$)$ (Table 4). 


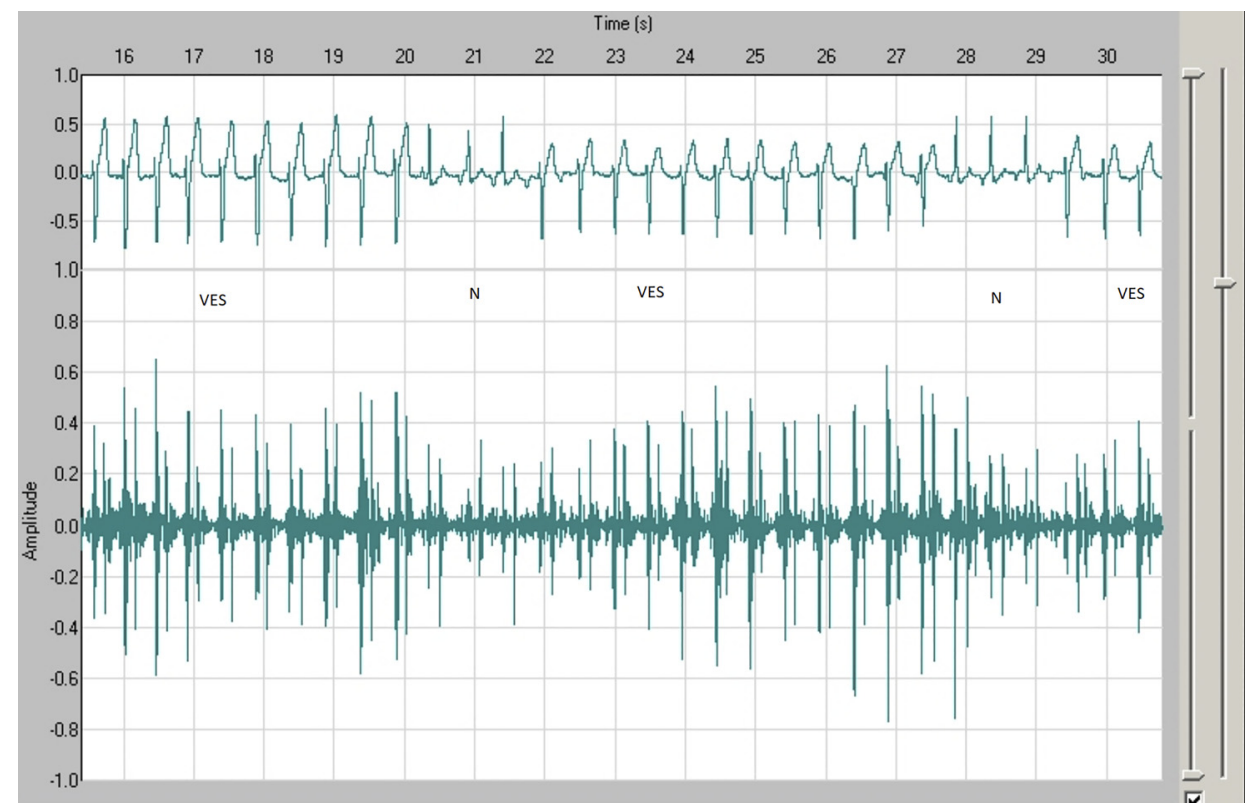

Fig. 5. Good-quality DPCG and ECG recording of a dog with paroxysmal ventricular tachycardia. The run of ventricular extrasystoles with abnormal ECG complexes is marked with the text VES whereas normal beats are marked with N. Note the seemingly random amplitude of both S1 and S2 beats on the DPCG during the VES episodes, and the relatively constant S1 and S2 amplitudes on the normal segments. Recording was made by the Welch Allyn Meditron Electronic Stethoscope

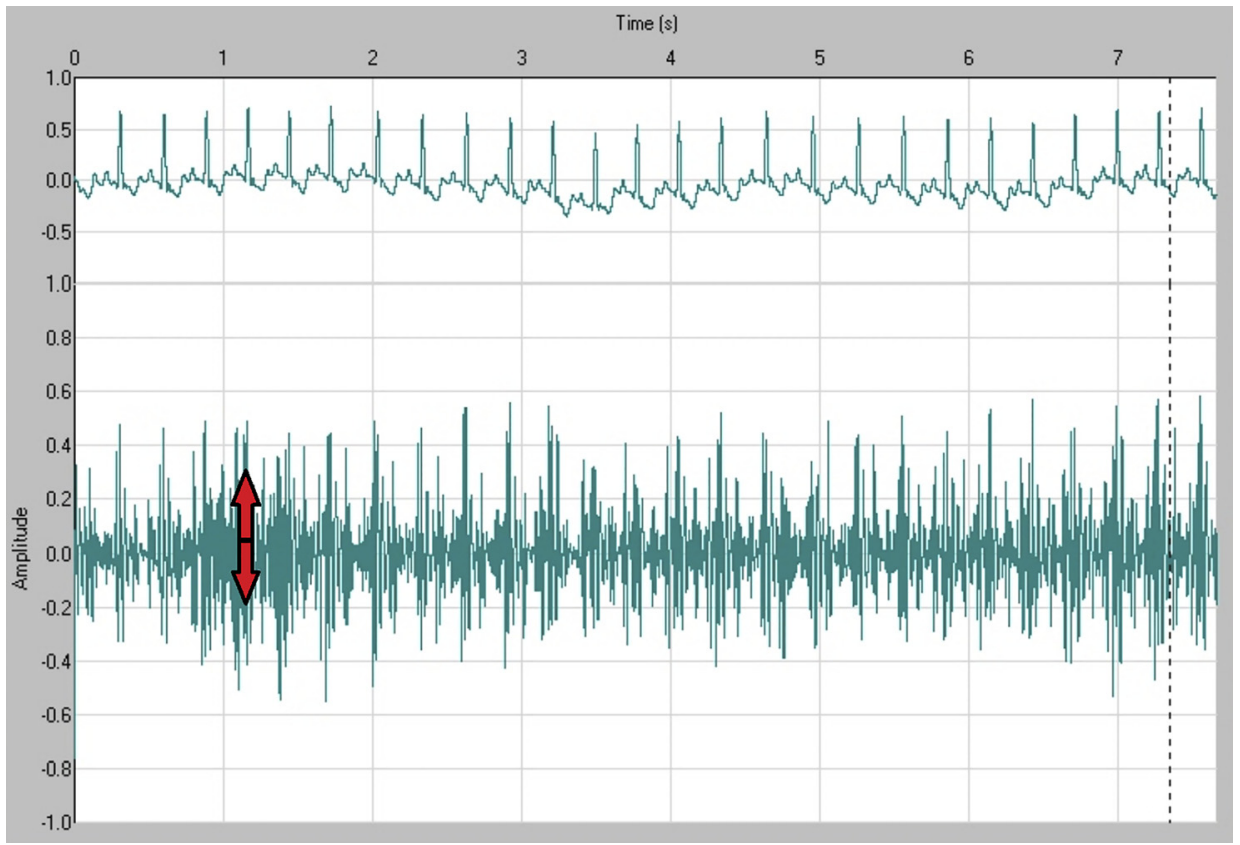

Fig. 6. Poor-quality DPCG with a large amount of baseline noise (red arrows) and ECG baseline deflection (as visible on the irregular baseline) of a dog with sinus tachycardia. Recording was made by the Welch Allyn Meditron Electronic Stethoscope. Note: the patient did not show signs of heart murmur that would explain DPCG baseline noise

\section{DISCUSSION}

Our study shows that electronic stethoscopes produce considerable auditory artefacts, but we were able to discern cardiac rhythms in many cases despite these artefacts. Furthermore, the Welch Allyn Meditron, which includes an
ECG that can be acquired simultaneously, provides a better means of analysing arrhythmias than the $3 \mathrm{M}$ Littmann 3200 electronic stethoscope, which does not provide simultaneous ECG recording. Neither stethoscope produced more or fewer phonocardiographic artefacts than the other; however, the number of cases that we could analyse was extremely low. 


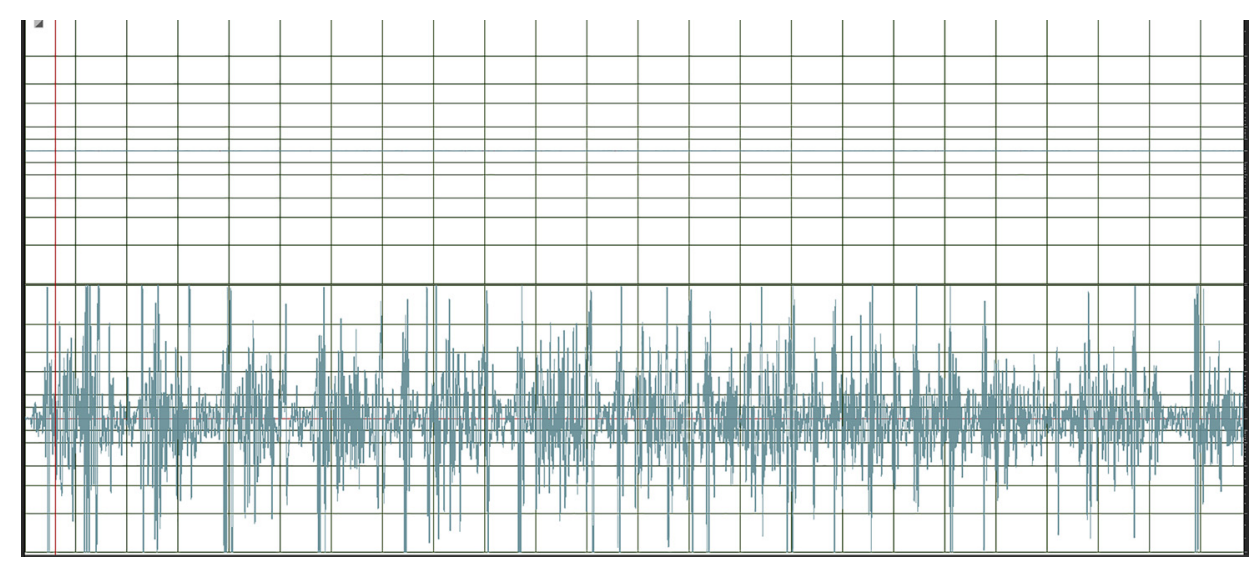

Fig. 7. Poor-quality DPCG with a very large amount of baseline noise, preventing the ability to properly interpret the results. Recording was made by the Littmann 3200 Electronic Stethoscope, from the same dog as in Fig. 6. Note: the patient did not show signs of heart murmur that would explain DPCG baseline noise

We previously showed that the Welch Allyn Meditron electronic stethoscope provided good-quality digital phonocardiograms of canine cardiac murmurs which were helpful in their diagnosis (Vörös et al., 2011). Based on our preliminary experiences with electronic stethoscopes and digital phonocardiography in the present study, these systems can help detect and document canine arrhythmias, in the same way as cardiac murmurs (Vörös et al., 2011; Szilvási et al., 2013; Marinus et al., 2017).

We used adhesive ECG electrodes while recording the phonocardiograms with the Welch Allyn Meditron to avoid artefacts caused by movement while auscultating dogs in a standing position (Vörös et al., 2011). However, unlike the auscultation of murmurs, the auscultation of arrhythmias does not depend on specific auscultatory locations and correct positioning of the dog (standing) but can be performed in right lateral recumbency which would allow standard ECG recording.

When comparing the two techniques, phonocardiograms recorded by the $3 \mathrm{M}$ Littmann 3200 stethoscope were less reliable for analysing arrhythmias, because, subjectively, the artefacts produced with this stethoscope made it difficult to identify true arrhythmias (Fig. 7). In addition, this stethoscope has a shorter recording period, which could limit arrhythmia detection. As the 3M Littmann 3200 stethoscope does not have a possibility to record synchronous ECGs on the phonocardiograms, ventricular systole and diastole can only be distinguished by identifying the 1st and the 2nd sounds on the phonocardiograms (Blass et al., 2013; Marinus et al., 2017). The identification of additional heart sounds becomes a challenge without synchronous ECG recordings and extrasystoles, even if identified, cannot be differentiated as originating from the atria or the ventricles.

On the other hand, the $3 \mathrm{M}$ Littmann 3200 system seems to be easier to use due to its Bluetooth connection $(<10 \mathrm{~m})$ to the computing device (computer and the relevant software).

For teaching and clinical research of pathological arrhythmias, the Welch Allyn Meditron system is more suitable because of its capability of synchronous phonocardiographic and ECG recordings on the digital phonocardiograms (Vörös
Table 2. Comparison of the number of artefacts of the ECG signals on the Innomed Holter and on the Welch Allyn Meditron DPCG recordings. The numbers represent the count of artefacts

\begin{tabular}{lcccc}
\hline Case & Breed & $\begin{array}{c}\text { Innomed } \\
\text { Holter }\end{array}$ & $\begin{array}{c}\text { Welch Allyn } \\
\text { Meditron }\end{array}$ & $\begin{array}{c}\text { ECG } \\
\text { diagnosis }\end{array}$ \\
\hline 1 & $\begin{array}{c}\text { Doberman } \\
\text { Pinscher }\end{array}$ & 0 & X & PSA \\
2 & American & 0 & 1 & SR \\
3 & Bulldog & & & PSA \\
4 & Mixed breed & 2 & 1 & PVT \\
5 & Rottweiler & 2 & 0 & SR \\
6 & Cane Corso & X & X & SR \\
7 & Sherman & 3 & 0 & SR \\
8 & Chihuahua & 2 & X & SR \\
9 & English & 2 & 0 & SR \\
9 & Bulldog & & & \\
10 & Bichon & 1 & 0 & PSA \\
\hline
\end{tabular}

PSA: physiologic sinus arrhythmia; SR: sinus rhythm; PVT: paroxysmal ventricular tachycardia; X: artefact number could not be evaluated due to high baseline noise.

et al., 2011; Szilvási and Vörös, 2014) as well as because of its reduced background noise due to noise filtering. This electronic stethoscope also provides audio recordings along with the phonocardiograms and ECGs. Consequently, the visual data accompanying the auditory data can help the listener to understand the sounds being auscultated (Ehlers et al., 2010; Vörös et al., 2010, 2011). Similarly, Naylor et al. (2001) used analogue (traditional) sound recordings of heart murmurs and arrhythmias of horses for teaching purposes with good results. To the best of our knowledge, there is no other similar publication in the literature.

Further digitalising techniques like spectral analysis, acoustic cardiography, and spectrophonocardiography - which are beyond the scope of this paper - can be used in the clinical research and teaching of cardiology (Tavel and Katz, 2005; Höglund et al., 2007; Ljungvall et al., 2009; Wen et al., 2014). 
Table 3. Comparison of the baseline noise on the digital phonocardiogram recordings with the Welch Allyn Meditron and with the 3M Littmann 3200 electronic stethoscopes. Values show the ratio between the highest audible heart sound to the baseline noise in pixels. Higher values mean lower noise

\begin{tabular}{|c|c|c|c|c|}
\hline Case & Breed & $\begin{array}{l}\text { Welch Allyn } \\
\text { Meditron }\end{array}$ & $\begin{array}{c}3 \mathrm{M} \\
\text { Littmann } \\
3200\end{array}$ & $\begin{array}{c}\text { ECG } \\
\text { diagnosis }\end{array}$ \\
\hline 1 & $\begin{array}{l}\text { Doberman } \\
\text { Pinscher }\end{array}$ & $\mathrm{X}$ & 5.6 & PSA \\
\hline 2 & $\begin{array}{l}\text { American } \\
\text { Bulldog }\end{array}$ & 3.5 & $\mathrm{X}$ & SR \\
\hline 3 & Mixed breed & 19.2 & 6 & PSA \\
\hline 4 & Rottweiler & $\mathrm{X}$ & $\mathrm{X}$ & PVT \\
\hline 5 & Cane Corso & $\mathrm{X}$ & 6.5 & SR \\
\hline 6 & $\begin{array}{c}\text { German } \\
\text { Shepherd Dog }\end{array}$ & 12.9 & $\mathrm{X}$ & SR \\
\hline 7 & Chihuahua & $\mathrm{X}$ & 4.2 & SR \\
\hline 8 & $\begin{array}{l}\text { English } \\
\text { Bulldog }\end{array}$ & 6.1 & $\mathrm{X}$ & SR \\
\hline 9 & $\begin{array}{l}\text { Bichon } \\
\text { Havanese }\end{array}$ & $\mathrm{X}$ & $\mathrm{X}$ & SR \\
\hline 10 & Mixed breed & 5.9 & $\mathrm{X}$ & PSA \\
\hline
\end{tabular}

PSA: physiologic sinus arrhythmia; SR: sinus rhythm; PVT: paroxysmal ventricular tachycardia; X: Signal-to-noise could not be evaluated due to the quality of the recording.

Table 4. Comparison of the count of artefacts on the DPCG recordings made with the Welch Allyn Meditron and with the $3 \mathrm{M}$ Littmann 3200 systems

\begin{tabular}{|c|c|c|c|c|}
\hline Case & Breed & $\begin{array}{l}\text { Welch Allyn } \\
\text { Meditron }\end{array}$ & $\begin{array}{c}3 \mathrm{M} \\
\text { Littmann } \\
3200\end{array}$ & $\begin{array}{c}\text { ECG } \\
\text { diagnosis }\end{array}$ \\
\hline 1 & $\begin{array}{l}\text { Doberman } \\
\text { Pinscher }\end{array}$ & $\mathrm{X}$ & 7 & PSA \\
\hline 2 & $\begin{array}{l}\text { American } \\
\text { Bulldog }\end{array}$ & 12 & $\mathrm{X}$ & SR \\
\hline 3 & Mixed breed & 2 & 12 & PSA \\
\hline 4 & Rottweiler & $\mathrm{X}$ & $\mathrm{X}$ & PVT \\
\hline 5 & Cane Corso & $\mathrm{X}$ & 11 & $\mathrm{SR}$ \\
\hline 6 & $\begin{array}{c}\text { German } \\
\text { Shepherd Dog }\end{array}$ & 3 & $\mathrm{X}$ & SR \\
\hline 7 & Chihuahua & $X$ & $\mathrm{X}$ & SR \\
\hline 8 & $\begin{array}{l}\text { English } \\
\text { Bulldog }\end{array}$ & 9 & $\mathrm{X}$ & SR \\
\hline 9 & $\begin{array}{l}\text { Bichon } \\
\text { Havanese }\end{array}$ & $\mathrm{X}$ & $\mathrm{X}$ & SR \\
\hline 10 & Mixed breed & 10 & $\mathrm{X}$ & PSA \\
\hline
\end{tabular}

PSA: physiologic sinus arrhythmia; SR: sinus rhythm; PVT: paroxysmal ventricular tachycardia; X: Could not be evaluated due to the quality of the recording.

A promising technique involves smartphone digital phonocardiography (Leng et al., 2015; Thoms et al., 2017).

Our study has some limitations as well, like the low number of cases analysed in detail and presented in the tables. We did not attempt to analyse the particular arrhythmias elicited by anaesthetic drugs, as this was not among the goals of the present study. As such, the different anaesthetic protocols used in our study did not influence our technical results.

Further noise reduction is also challenging with native phonocardiograms produced by the Welch Allyn Meditron electronic stethoscope, as neither Audacity, nor Adobe Audition FFT (Fourier Transform Filter) filters support a single channel application (the audio channel, with the ECG tracings being recorded in the second channel).

It is worth noting that the Welch Allyn Meditron is no longer produced; therefore, some of the artefact issues we observed might have been addressed with newer electronic stethoscopes that might include better filters both for the audio signals and the ECG signals. The 3M Littmann 3200 remains available but has not been updated to include a simultaneous ECG recording.

Our preliminary observations suggest that electronic stethoscopes, when coupled with simultaneously obtained ECG recordings, might help educate veterinary students about cardiac arrhythmias as well as murmurs.

\section{ACKNOWLEDGEMENT}

This study was supported by the Doctoral School of the University of Veterinary Medicine Budapest as part of the doctoral thesis of the first author.

\section{REFERENCES}

Blass, K. A., Schober, K. E., Bonagura, J. D., Scansen, B. A., Visser, L. C., Lu, J. and Smith, N. D. (2013): Clinical evaluation of the 3M Littmann Electronic Stethoscope Model 3200 in 150 cats. J. Feline Med. Surg. 15, 893-900.

Bonagura, J. D. and Fuentes, W. L. (2015): Echocardiography. In: Nyland, T. G. and Mattoon, J. S. (eds) Small Animal Diagnostic Ultrasound. 3rd edition. Elsevier Saunders, St. Louis. pp. 217331.

Brown, D., Gaillot, H. and Cunningham, S. (2015): Heart. In: Penninck, D. and d'Anjou, M. A. (eds). Atlas of Small Animal Ultrasonography. 2nd edition. Blackwell Publishing, Ames. pp. $111-181$

Caivano, D., Dickson, D., Martin, M. and Rishniw, M. (2018): Murmur intensity in adult dogs with pulmonic and subaortic stenosis reflects disease severity. J. Small Anim. Pract. 59, 161166.

Dahl, L. B., Hasvold, P., Arild, E. and Hasvold, T. (2002): Heart murmurs recorded by a sensor based electronic stethoscope and e-mailed for remote assessment. Arch. Dis. Child. 87, 297-301.

Edwards, N. J. (1987): Bolton's Handbook of Canine and Feline Electrocardiography. 2nd edition. W. B. Saunders, Philadelphia. pp. 16-31.

Ehlers, J. P., Vörös, K., Tipold, A. and Nolte, I. (2010): Teaching the examination of the dog's heart in a blended learning setting An effective way to use 'new media'. GMS Med. Inform. Biometry Epidemiol. (MIBE) 6(2), 1-10. www.egms.de/static/ en/journals/mibe/2010-6/mibe000107.shtml. 
Fraune, A. (2010): Phono- and Echocardiographic Monitoring for the Evaluation of Heart Murmurs in Horses [in German]. Dissertation. Faculty of Veterinary Medicine, Free University of Berlin.

Germanakis, I., Dittrich, S., Perakaki, R. and Kalmanti, M. (2008): Digital phonocardiography as a screening tool for heart disease in childhood. Acta Pediatr. 97, 470-473.

Germanakis, I. and Kalmanti, M. (2009): Paediatric cardiac auscultation teaching based on digital phonocardiography. Med. Educ. 43, 489.

Grenier, M. C., Gagnon, K., Genest, J., Durand, J. and Durand, L-G. (1998): Clinical comparison of acoustic and electronic stethoscopes and design of a new electronic stethoscope. Am. J. Cardiol. 81, 653-656.

Hoyte, H., Jensen, T. and Gjesdal, K. (2005): Cardiac auscultation training of medical students: a comparison of electronic sensorbased and acoustic stethoscopes. BMC Med. Ed. 5, 14.

Höglund, K., Ahlstrom, C. H. G., Häggström, J., Ask, P. N. A., Hult, P. H. P. and Kvart, C. (2007): Time-frequency and complexity analyses for differentiation of physiologic murmurs from heart murmurs caused by aortic stenosis in Boxers. Am. J. Vet. Res. 68, 962-969.

Kvart, C. and Häggström, J. (2002): Cardiac Auscultation and Phonocardiography in Dogs, Horses and Cats. TK i Uppsala AB, Uppsala. pp. 13-20.

Leng, S., Tan, R. S., Chai, K. T. C., Wang, C., Ghista, D. and Zhong, L. (2015): The electronic stethoscope. BioMed. Eng. OnLine 14, 66.

Ljungvall, I., Ahlstrom, C., Höglund, K., Hult, P., Kvart, C., Borgarelli, M., Ask, P. and Häggström, J. (2009): Use of signal analysis of heart sounds and murmurs to assess severity of mitral valve regurgitation attributable to myxomatous mitral valve disease in dogs. Am. J. Vet. Res. 70, 604-613.

Ljungvall, I., Rishniw, M., Porciello, F., Ferasin, L. and Ohad, D. G. (2014): Murmur intensity in small-breed dogs with myxomatous mitral valve disease reflects disease severity. J. Small Anim. Pract. 55, 545-550.

Mahnke, C. B., Mulreany, M. P., Inafuku, J., Abbas, M., Feingold, B. and Paolillo, J. A. (2008): Utility of store-and-forward pediatric telecardiology evaluation in distinguishing normal from pathologic pediatric heart sounds. Clin. Pediatr. 47, 919-925.

Marinus, S. M., van Engelen, H. and Szatmári, V. (2017): N-Terminal Pro-B-type natriuretic peptide and phonocardiography in differentiating innocent cardiac murmurs from congenital cardiac anomalies in asymptomatic puppies. J. Vet. Intern. Med. 31, 661-667.

Naylor, J. M., Yadernuk, L. M., Pharr, J. W. and Ashburner, J. S. (2001): An assessment of the ability of diplomates, practitioners, and students to describe and interpret recordings of heart murmurs and arrhythmia. J. Vet. Intern. Med. 15, 507515.

Noponen, A-L., Lukkarinen, S., Angerla, A. and Sepponen, R. (2007): Phono-spectrographic analysis of heart murmur in children. BMC Pediatr. 7, 23.
Philip, J. H. and Raemer, D. B. (1986): An electrical stethoscope is judged better than conventional stethoscopes for anesthesia monitoring. J. Clin. Monit. 2, 151-154.

Reisse, A. (2008): Phonocardiographic Investigations of Heart Murmurs in Cattle [in German]. Dissertation. Ludwig Maximilian University, Faculty of Veterinary Medicine, Munich.

Rishniw, M. (2018): Murmur grading in humans and animals: past and present. J. Vet. Card. 20, 223-233.

Szilvási, V. and Vörös, K. (2014): Application of sensor-based electronic stethoscopes and digital phonocardiography in canine cardiology [in Hungarian, with English abstract]. Magy. Allatorvosok 136, 291-299.

Szilvási, V., Vörös, K., Manczur, F., Reiczigel, J., Novák, I., Máthé, Á. and Fekete, D. (2013): Comparison of traditional and sensorbased electronic stethoscopes in Beagle dogs. Acta Vet. Hung. 61, 19-29.

Tavel, M. E. (1996): Cardiac auscultation. A glorious past - but does it have a future? Circulation 93, 1250-1253.

Tavel, M. E. (2006): Cardiac auscultation. A glorious past - and it does have a future! Circulation 113, 1255-1259.

Tavel, M. E. and Katz, H. (2005): Usefulness of a new sound spectral averaging technique to distinguish an innocent systolic murmur from that of aortic stenosis. Am. J. Cardiol. 95, 902904.

Thoms, L-J., Colicchia, G. and Girwidz, R. (2017): Phonocardiography with a smartphone. Phys. Educ. 52, 023004.

Tilley, L. P. and Burtnick, N. L. (2009): ECG for the Small Animal Practitioner. Made Easy Series. Teton New Media, Jackson, USA. pp. 17-32.

Vörös, K., Balogh, M., Kleinsorgen, Ch., Manczur, F. and Nolte, I. (2010): Heartsound library. https://www.tiho-hannover.de/ studium-lehre/zelda/e-learning-beratung/lernmedien-undlernprogramme/heartsound-library) Last accessed: 29 April 2020.

Vörös, K., Bonnevie, A. and Reiczigel, J. (2012): Comparison of conventional and sensor-based electronic stethoscopes in detecting cardiac murmurs of dogs. Tierärztl. Prax. Ausgabe K, Kleintiere Heimtiere 40, 103-111.

Vörös, K., Nolte, I., Hungerbühler, S., Reiczigel, J., Ehlers, J. P., Tater, G., Mischke, R., Zimmering, T. and Schneider, M. (2011): Sound recording and digital phonocardiography of cardiac murmurs in dogs by using a sensor-based electronic stethoscope. Acta Vet. Hung. 59, 23-35.

Vörös, K., Szilvási, V., Manczur, F., Máthé, Á., Reiczigel, J., Nolte, I., Hungerbühler, S. (2015): Occurrence of mitral valve insufficiency in clinically healthy Beagle dogs. Acta Vet. Hung. 63, 458-471.

Wen, Y. N., Lee, A. P., Fang, F., Jin, C. N. and Yu, C. M. (2014): Beyond auscultation: acoustic cardiography in clinical practice. Int. J. Cardiol. 172, 548-560.

Zenk, B. M., Bratton, R. L., Flipse, T. R., and Page, E. E. (2004): Accuracy of detecting irregular cardiac rhythms via telemedicine. J. Telemed. Telecare 10, 54-58.

Open Access. This is an open-access article distributed under the terms of the Creative Commons Attribution 4.0 International License (https://creativecommons.org/ licenses/by/4.0/), which permits unrestricted use, distribution, and reproduction in any medium, provided the original author and source are credited, a link to the CC License is provided, and changes - if any - are indicated. (SID_1) 